\title{
El efecto Mateo y la selección documental de elementos onomásticos en información audiovisual televisiva
}

\author{
Por Jorge Caldera-Serrano
}

\begin{abstract}
Resumen: Se presenta la extrapolación del efecto Mateo a la selección documental de información onomástica audiovisual para televisión atendiendo al principio de redundancia informativa visual. Se pretende ayudar a la toma de decisión sobre la pertinencia visual de personas y entidades analizando su frecuencia de aparición. Para ello se han estudiado "escaletas" y despachos de agencias (teletipos) para conocer dicha frecuencia. La finalidad es determinar en qué momento un personaje y/o entidad cuenta con un grado de presencia visual en el depósito audiovisual que conduzca a su no inclusión en la base de datos de la cadena.
\end{abstract}
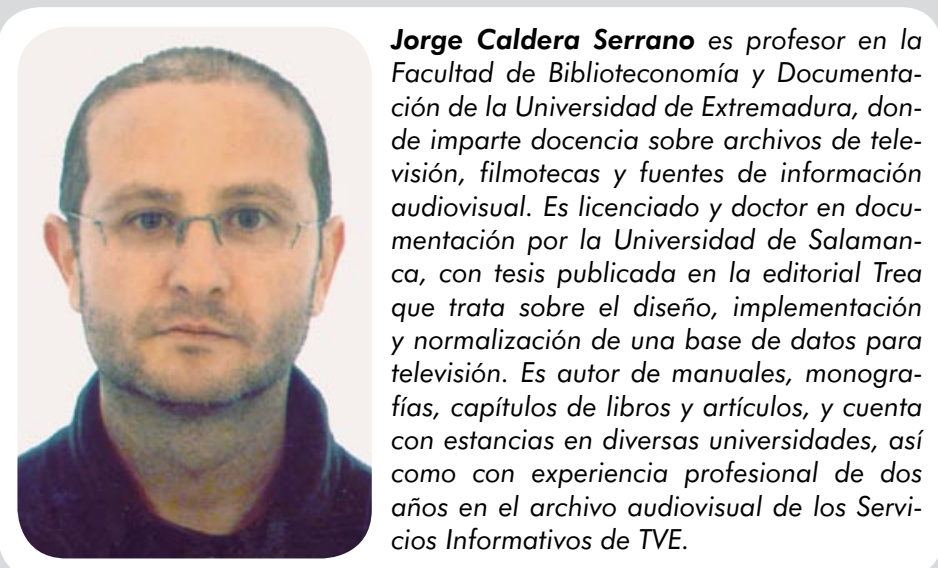

Palabras clave: Información audiovisual, Televi-

sión, Efecto Mateo, Selección de documentos, Información onomástica.

\section{Title: The Matthew effect and record selection for onomastic items in televised audiovisual material}

Abstract: The Matthew effect concept is applied to record selection for onomastic information on television, with attention to the principle of visual information redundancy. The intent is to guide decision making about the visual relevance of people and organizations by analyzing the frequency with which they appear on television. Broadcast schedules/logs and press agency dispatches are studied with the goal of determining the level of visual presence in the audiovisual archives at which images of a person and/or entity are no longer added to a media database.

Keywords: Audiovisual information, Television, Matthew effect, Record selection, Onomastic information.

Caldera-Serrano, Jorge. "El efecto Mateo y la selección documental de elementos onomásticos en información audiovisual televisiva". En: El profesional de la información, 2007, septiembre-octubre, v. 16, n. 5, pp. 409-415.

DOI: 10.3145/epi.2007.sep.02

\section{Introducción}

Robert K. Merton (1968) acuña el término "efecto Mateo" a la vista del comportamiento de los autores firmantes de los documentos científicos. Se basa en un principio extremadamente sencillo pero a la vez muy acertado: aquellos autores que se citan más por otros colegas, serán también más citados en el futuro por otros. Las motivaciones son diversas y variadas, por lo que animamos a la lectura del material de Merton para su profundización, a Strevens (2006) para su mejor comprensión y a Bonitz (2005) y Havemann (2005) para su validación.
Existen algunos autores, ya clásicos, que son citados por el simple hecho de ser imperdonable su no presencia en ciertos textos. A veces, el carácter acumulativo de la ciencia da paso a una falsa adulación de las personas consagradas. No obstante, se ha de considerar que el efecto Mateo no sólo se produce en el análisis de citas sino también en otros ámbitos sociales, y sucede como con las leyes de Zipf, Lotka y Bradford, que son principios dinámicos que se cumplen con independencia del universo estudiado.

Todo comienza cuando existen determinados autores que por motivos diversos consiguen el recono- 
cimiento del colectivo de autores y de editores. Estos últimos valoran de forma más flexible los trabajos en caso de contar con personas reconocidas entre los firmantes. A mayor número de artículos y mayor prestigio más citación, y más fácil la publicación, y por tanto mayor citación. Esta espiral a veces sin ningún tipo de fundamento intelectual es, en resumidas cuentas, el efecto Mateo. La denominación proviene de la Biblia, del capítulo 13, versículo 12 del Evangelio según San Mateo, que dice literalmente: "Porque al que tiene se le dará y tendrá en abundancia; pero al que no tiene incluso lo que tiene se le quitará”.

Este fenómeno de sobrevisibilidad (y de invisibilidad para coautores nóveles eclipsados por los investigadores reconocidos) es extrapolable no sólo a personajes sino que puede ser válido para centros de investigación y colegios invisibles, donde será complicado que los grupos emergentes puedan hacerse un sitio.

La bibliometría, definida un año más tarde por Pritchard (1969), debería tener más presente este factor que tendría que ser corrector de los estudios puramente cuantitativos. Price (1963) formula la ley bibliométrica en la cual defiende el crecimiento exponencial de la ciencia, protegiendo sus detractores el concepto de saturación por razones socioeconómicas, políticas y culturales. Este elemento, la saturación, junto a la "función de redundancia", han sido tomados como base y punto de partida para el desarrollo metodológico de este trabajo.

Merton expone su hipótesis centrándose en el ámbito científico, y más expresamente, en la forma de comunicación de sus resultados; sin embargo apostamos por extrapolar este proceso a otro igualmente comunicativo, pero no científico sino sociológico, como es el caso de los medios de comunicación televisivos.

¿Qué se pretende demostrar? Los procesos productivos y de difusión en televisión se centran en la comunicación de información de actualidad. Esta información cuenta con una serie de sujetos activos y pasivos que deberán ser conservados o desechados en los archivos de televisión para su posterior reutilización. Una noticia nunca es un hecho aislado, sino que tiene relación con unos antecedentes y cuenta con una serie de consecuentes, por lo que se desea mostrar que genera otras nuevas y diferentes que llevan asociadas imágenes prácticamente iguales. Tanto es así, que se llega a una saturación visual en el archivo al contar con imágenes grabadas con días de diferencia, lo que acarrea problemas de espacio físico y de redundancia a la hora de la recuperación de la información.

¿Cuál es el fin de este artículo? Tomar como hipótesis válida la existencia del efecto Mateo en los medios de comunicación a la hora de visualizar la presencia

\section{"La saturación visual acarrea problemas de espacio físico y de redundancia en la recuperación"}

de personajes en pantalla, lo cual nos ayudará a fijar un método en el cual quede plasmado un esquema de selección de elementos visuales de personas físicas y entidades.

En resumen, y llevado a la práctica, si un acontecimiento hace necesaria la presencia en pantalla del mismo personaje durante dos semanas en los informativos, no será preciso conservarlo en todas las actuaciones sino en aquella o aquellas que se consideren más significativas visualmente. El estudio analiza el aspecto visual y no temático, ya que un mismo personaje podría ser seleccionado por criterios diferentes a los indicados (declaraciones, relaciones o presencia con otros personajes, etc.). Sin embargo la práctica profesional demuestra que en la mayor parte de los casos la conservación de los elementos onomásticos está más relacionada con lo visual, que es más estable, que con lo sonoro, que es más efímero.

\section{Metodología desarrollada en el proceso de investigación}

Como método analítico se muestra la siguiente observación: una información genera otros hechos noticiosos hasta que desaparece al dejar de tener un valor informativo (saturación). Para demostrar esta hipótesis se han analizado dos elementos diferentes: despachos de agencia (teletipos) y escaletas de las emisiones de los informativos.

Los primeros son las informaciones textuales que ofrecen las agencias de información a los medios abonados a sus servicios. Se ha utilizado la colección de la agencia EFE, que se ha extraído de The Cross-Language Evaluation Forum (CLEF). El corpus cuenta con un total de 16.548 , lo que corresponde a los teletipos comercializados de EFE en el año 1994 (figura 1).

\begin{tabular}{|l|l|}
\hline 31 diciembre 1994 & VARIOS líneas \\
\hline IBM-WATSON. Fallecido hijo fundador empresa de computadoras \\
\hline Nueva Cork, 31 dic (EFE). - Thomas Watson junior, hijo del fundador de \\
Internacional Business Machines Corp. (IBM), falleció hoy, viemes, en un \\
hospital del estado de Cornecticut a los 79 años de edad, informó un portavoz \\
de la empresa. \\
Watson falleció en el hospital Greenwich a consecuencia de complicaciones \\
tras sufrir un ataque cardiaco, añadió la fuente. \\
El difunto heredó de su padre una empresa dedicada principalmente a la \\
fabricación de máquinas de escribir y la transformó en una compañía líder e \\
innovadora en el mercado de las computadoras. \\
PD/FMR
\end{tabular}

Figura 1. Teletipo 


\begin{tabular}{|c|c|}
\hline $15: 00: 00$ & SALUDOS, CABECERA, TITULARES \\
\hline 15:02:35 & $\begin{array}{l}\text { DIRECTO CON ESTRELLA MORENO, QUIEN INFORMA DE LOS } \\
\text { TEMAS QUE AZNAR Y MAYOR ESTAR TRATANDO EN SU } \\
\text { REUNIONEN LONDRES }\end{array}$ \\
\hline 15:05:06 & $\begin{array}{l}\text { PRINCIPIO DE ACUERDO ENTRE LOS SINDICATOS Y LA } \\
\text { PATRONAL DE TRANSPORTISTAS FRANCESES, AUNQUE LA } \\
\text { HUELGA CONTINUA }\end{array}$ \\
\hline 15:07:51 & $\begin{array}{l}\text { LA AUDIENCIA NACIONAL PEDIRA LA EXTRADICION DEL } \\
\text { ETARRA JUAN LUIS AGUIRRE LETE, CAPTURADO AYER EN } \\
\text { FRANCIA } \\
{[\ldots]}\end{array}$ \\
\hline & DEPORTES \\
\hline $15: 30: 5$ & $\begin{array}{l}\text { BRITO ARCEO ARBITRARA EL PROXIMO PARTIDO REAL } \\
\text { MADRID-BARCELONA } \\
{[\ldots]}\end{array}$ \\
\hline 15:39:1 & FIN \\
\hline
\end{tabular}

Figura 2. Escaleta

El otro elemento analizado, mucho más fiable, son las escaletas de los informativos. Para ello se ha recurrido a la colección de escaletas de Televisión Española del año 1998. Éstas representan una serie de datos de control sobre la emisión del informativo para después ir desgranando cada una de las noticias que componen el noticiario. Es una labor realizada por el Departamento de Documentación en el que se indica preferentemente el quién y el qué de las noticias informativas (figura 2).

Se han analizado en cada una de ellas cinco informaciones seleccionadas al azar en cada mes, siguiendo su análisis y búsqueda hasta que perdían su vigencia. En el caso de teletipos se ha hecho por medio de su texto completo, y en el de las escaletas a través de los titulares aportados por los documentalistas. Con posterioridad, en el apartado de resultados, se muestran las líneas resultantes y las diferentes casuísticas, y se indicarán las fórmulas de control para la selección de elementos de personas.

\section{Comprobación de la hipótesis inicial}

En primer lugar hay que indicar que las curvas entre el análisis de información de agencia internacional y de las escaletas son prácticamente idénticas. La diferencia fundamental radica en el arrastre informativo por parte de las agencias; es decir, una información sigue siendo

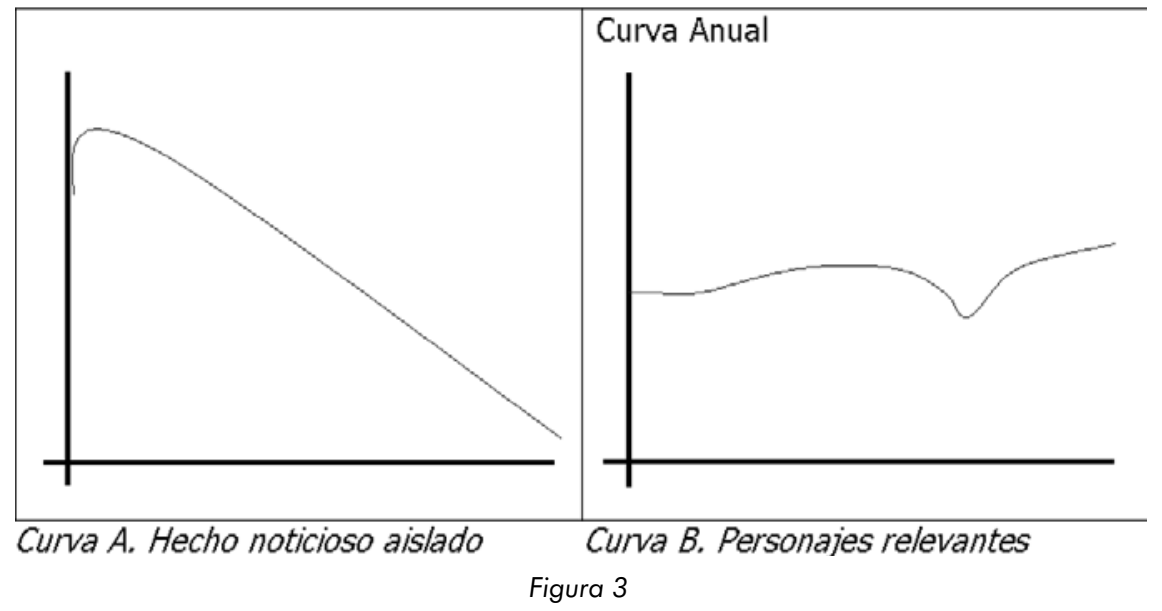

durante más tiempo noticia para las agencias que para televisión, ya que en ésta última la validez informativa se recorta en el tiempo de manera ostensible. Otro elemento diferenciador es que la cobertura temática y geográfica es más amplia para las agencias y más cercana para la televisión.

Por lo tanto, y tras mostrar estos paralelismos con diferencias poco relevantes, nos centramos en el análisis de las escaletas, documento referencial que refleja con exactitud el contenido de las noticias que componen cada uno de los informativos.

Por cuestión de operatividad se ha analizado únicamente el informativo de prime time de la cadena seleccionada, ya que tanto los informativos matinales como vespertinos son normalmente una variación de éste. Aunque esperado, se han detectado dos curvas absolutamente diferentes a la hora de identificar los personajes involucrados en la información (figura 3).

La curva A representa la frecuencia de aparición de personajes relacionados con un hecho noticioso puntual, aislado. Una noticia ocurre como reflejo de una sociedad por acciones sociales, económicas, deportivas o de cualquier otra índole. Un accidente de aviación puede contar con una relación temática de siniestros anteriores, sin embargo el hecho en sí mismo es único, irrepetible e individual. Dicho acontecimiento provocará la generación de una serie de informaciones a raíz de la anterior. Recordemos una realidad: la existencia del periodismo declarativo; casi nunca la televisión se encuentra en el lugar del acontecimiento, por lo que se contará con reacciones, comentarios, discursos relacionados con el suceso, etc.

En esta primera curva la línea de tiempo varía entre días o meses dependiendo de la vigencia informativa del hecho noticioso, sin embargo la forma y tendencia de la curva es constante.

También existen hechos puntuales sin tanta presencia en los medios. La hambruna endémica en Sierra Leona es una realidad que sólo de vez en cuando aparece como información televisiva. El "Efecto Mateo" está fuera de lugar para esta casuística y a la hora de la selección de información onomástica deberá analizarse otra serie de parámetros como vigencia informativa, importancia de los personajes visualizados, potencialidad de utilización posterior, entre otros elementos.

La curva A nos muestra que los personajes que son motivo de una información cuentan posteriormente con mayor posibilidad de seguir 
siéndolo de nuevas noticias. Ahora bien, se podría indicar que en ciencia, la citación de trabajos de autores relevantes no cae de forma tan significativa. Es cierto, pero se debe tener en cuenta que el ámbito aquí estudiado es el de la comunicación de información social-periodística, que alcanza el nivel de saturación con mayor rapidez que la información científica.

\section{"Los personajes que son motivo de una información cuentan posteriormente con mayor posibilidad de seguir siéndolo de nuevas noticias"}

La curva B es mucho más normal de lo que podría preverse, ya que corresponde a personajes relevantes para la sociedad. Por ejemplo, los dirigentes políticos y deportistas más destacados cuentan con una presencia prácticamente continua en los informativos de la cadena. Esto no significa que sean siempre los personajes principales de cada información; sin embargo deben y tienen mucho que contar ante las diferentes noticias.

El nivel de saturación coincide con la vigencia de sus cargos. Un ejemplo de ello es la presencia del expresidente de gobierno José María Aznar, prácticamente nula actualmente y casi diaria durante la época de su mandato. Otro caso podría ser la presencia de futbolistas en las pantallas, que es casi constante durante el período en que juegan en un equipo "grande": Ronaldo, exjugador del Real Madrid y del F. C. Barcelona, ha contado con escasos momentos televisivos antes y después de pertenecer a estos equipos, y sin embargo su presencia era prácticamente diaria durante los años en que jugó en ellos.

¿Pero es posible que la curva B sólo se corresponda con personas físicas? En absoluto. Existen otros hechos de presencia constante en los informativos como son los principales equipos del país de las diferentes competiciones deportivas. En toda Europa el fútbol cuenta con un alto seguimiento mediático, lo que se traduce en espectaculares audiencias tanto en programas informativos como en retransmisiones en directo.

Se observa como la curva B cuenta con una bajada que, dependiendo de la temática, puede ser más acusada; correspondería con la finalización del curso político o de las competiciones deportivas con motivo del parón estival. Aunque pudiera creerse que esto es un asunto baladí no lo es en absoluto. Durante estos períodos las noticias en muchos casos son auténticamente de relleno, y tienen más cabida informaciones culturales, así como otras más "blandas" que no hubieran sido emitidas en pleno curso político. Los reportajes de valoración sustituyen a las crónicas informativas. Además, y como curiosidad, la utilización de información de archivo es mucho mayor al haber menos reporteros grabando en las calles.

\section{La selección de información audiovisual de personas en televisión}

Son muchas las cuestiones y aspectos que faltan por normalizar en estos archivos, pero especialmente preocupante es la falta de políticas claras de selección así como el desarrollo de las normativas que profundicen en criterios generales.

\section{"Especialmente preocupante es la falta de políticas claras de selección así como el desarrollo de las normativas que profundicen en criterios generales"}

Se han de tener en cuenta diferentes variantes a la hora de realizar la selección, a saber (Caldera; Nuño, 2004):

- Redundancia informativa. La información periodística es redundante en la temática, presencia de personas connotadas y denotadas.

- Características técnicas. Las malas características físicas por una grabación defectuosa o por defectos intrínsecos del soporte hacen que su reutilización sea complicada. No obstante tendremos que tener en cuenta su exclusividad como punto de partida, es decir, imágenes únicas (aunque en mal estado) deberán ser analizadas y conservadas.

- Recursos humanos. Las limitaciones de personal y el arduo trabajo obligan a seleccionar. Esta cuestión es un factor determinante no sólo para la selección, sino también para especificar el nivel de análisis. El tratamiento no se acomoda a las necesidades reales del usuario sino a las posibilidades reales de los documentalistas.

- Limitaciones económicas. Derivadas de la contratación de personal y del coste de los soportes de captación de imágenes (cintas de vídeo).

- Restricciones espaciales. Otro factor es la ocupación física de los soportes, requiriendo espacios amplios para su ubicación. La digitalización abarata los procesos de realización, producción y también de conservación. No obstante, al no existir equipos con capacidad de almacenamiento suficiente para miles de horas de información audiovisual, es necesaria la adquisición de robots donde se almacena información digital en cintas analógicas. 
Los criterios de selección recomendados por la $\mathrm{Co}$ misión de Preservación y Selección de la Federación Internacional de Archivos de Televisión, y recogidos por Hanford (1986) son demasiado ambiguos para una selección correcta del material audiovisual. Se señala la necesidad de seleccionar "material sobre historia y desarrollo de la televisión (...) en el que aparezca gente de interés histórico (...) acontecimientos de interés histórico (...) de interés sociológico (...) que muestre objetos, como obras de arte, edificios, maquinaria y equipamientos, etc. Material que muestre lugares geográficos (...) programas individuales o series de programas (...)".

La realidad en la práctica totalidad de las cadenas televisivas es la conservación de todo aquel material que ha sido emitido, y a partir de esta premisa los siguientes criterios son bastantes más vagos y confusos. Otro problema señalado por Hidalgo (1999) es la decisión de quién decide el expurgo, algo que sigue siendo considerado como "tramar un asesinato". Parece oportuna la creación de un equipo multidisciplinar para llevarlo a cabo, que analice cuestiones documentales, legales, técnicas, económicas y sociológicas.

\section{"La realidad es la conservación de todo aquel material que ha sido emitido, y a partir de esta premisa los siguientes criterios son bastantes más vagos y confusos"}

Sobre la conservación específicamente de elementos onomásticos han de tenerse en cuenta, además de los señalados, otros aspectos como los cambios en el aspecto físico de los personajes. Es decir, no sólo nos referimos al paso del tiempo y al irremediable envejecimiento, sino también a sus posibles variaciones de aspecto.

También se debe tener presente que no se puede ofrecer un documento antiguo para información de actualidad. La gran "mentira" de la televisión es utilizar material de archivo como si fuera actual. Cuando el documento es claramente de archivo incluso se refleja en la rotulación de la pantalla, mientras que la información grabada recientemente no suele referenciarse como tal.

Otro elemento, derivado del anterior, es la necesidad de contar con información acorde a la temporada del año para que pueda parecer real. Indico un ejemplo: una solicitud al archivo en época veraniega no podrá ser resuelta ofreciendo material
"Una solicitud en época veraniega no podrá ser resuelta ofreciendo material de un personaje con abrigo y gorro de lana"

de un personaje con abrigo y gorro de lana. La coherencia visual debe primar por encima de parámetros incluso estéticos cuando se desea que el material pase por actual.

Con todo lo expuesto hasta ahora, presentamos una "Ficha de control de selección de personas", que deberá ser implementada computacionalmente. A partir de dicha herramienta organizaremos la selección documental (figura 4).

Se conforma una ficha de control en la que se indican, en primer lugar, el "Nombre" de la persona física y la "Entidad" (organización relacionada con el personaje), elementos que deben ser acordes con el índice de control de autoridades.

Posteriormente, en el apartado de "Control temporal", se indica el "Año" y la "Fecha" de su última imagen conservada, incluyendo la información de registros anteriores. Junto a ambos se indicará el hiperenlace al documento electrónico para poder visualizarlo a través de la intranet.

Por último, en la "Descripción" se ofrecerá información para determinar si es un "Recurso" o un "Total", así como las condiciones atmosféricas o de vestimenta (invierno/verano). En el caso de información realizada en estudio o en interior las condiciones atmosféricas se anulan.

Se denominan totales los documentos en los que lo que interesa conservar es la locución del personaje, como declaraciones, ruedas de prensa, entrevistas; y recursos los que muestran al personaje realizando una acción, como subiendo al coche, saludando a ancianos, besando a niños, jugando al tenis, etc.

Recordemos que tanto las noticias aisladas como en información en que los personajes están relacionados

\begin{tabular}{|c|c|c|c|c|c|}
\hline \multicolumn{6}{|c|}{ Ficha de control de selección de personas } \\
\hline \multicolumn{6}{|c|}{\begin{tabular}{l|l} 
Nombre & \\
\end{tabular}} \\
\hline \multicolumn{6}{|l|}{ Entidad } \\
\hline \multicolumn{6}{|c|}{ CONTROL TEMPORAL } \\
\hline Año & $\nabla$ & & Fecha & & $\boldsymbol{\nabla}$ \\
\hline \multicolumn{6}{|c|}{ Hiperenlace } \\
\hline \multicolumn{6}{|c|}{ DESCRIPCIÓN } \\
\hline Recurso & & & Total & & $\square$ \\
\hline Invierno & $\square$ & Verano & $\square$ & Interior & $\square$ \\
\hline
\end{tabular}

Figura 4. Ficha de control de selección de personas 
con diferentes eventos, son redundantes visualmente, por lo que no deberá controlarse y conservarse toda la información generada en torno a éstos. Por ello planteamos la necesidad de mantener recursos y totales de estos personajes en determinadas ocasiones a lo largo de un año (cada empresa deberá organizar su trabajo conforme a sus estadios organizativos).

\section{Las personas físicas y totales}

Partimos de la concepción de que el periodismo es declarativo, que la inmensa mayoría de las veces que aparece un personaje es hablando y visualmente consiste en un plano medio fijo. Los totales cuentan con una vigencia informativa bastante efímera salvo en casos donde lo declarado es a todas luces importante. También recordamos que el material emitido se conserva y el periodista selecciona aquellos cortes de voz más interesantes del personaje, por lo que el esfuerzo para el control de los totales ha de ser relativo en lo concerniente a los brutos.

No obstante, se deberán conservar al menos en dos ocasiones: una de ellas en interior y otra en exterior, independientemente de la época del año, debido a que el material de interior es mucho más atemporal y se podrá ofrecer independientemente de las condiciones atmosféricas. Queda evidenciado que será utilizado como relleno y que el material sonoro en sí carece de valor para esta información. Conservamos información actual con vistas a un valor de uso futuro.

Se conservará anualmente mientras el personaje cuente con valor informativo (que dependerá de la ponderación de la presencia, su importancia y las solicitudes de los usuarios de nuestro archivo). En aquellos casos en los que la persona no cuenta con tanta validez, se conservará la primera vez que aparezca como elemento principal de la información, volviendo a conservarlo cuando se observa una bajada en la validez informativa. No debería ser complicado realizar dicha observación si se tiene presente que el documentalista debe seguir la actualidad de forma continuada.

\section{Las personas físicas y los recursos}

Los recursos cuentan con mayor utilización que los totales. Se tiene al personaje realizando una acción, y la televisión es por definición movimiento. Los documentos cuentan con una duración mayor, lo que se traduce en ciertas ventajas. ¿En qué sentido? Normalmente un documento pedido al archivo para utilizarlo no va a ser requerido en su totalidad, sino que se seleccionarán breves fragmentos, segundos, por lo que podrán

\section{"La ficha optimiza recursos humanos, espaciales y sustancialmente documentales, rebajando considerablemente el ruido en la recuperación"}

utilizarse partes diferentes sin tener que repetir el fragmento visual.

Las acciones se conservarán tanto en invierno (con ropa que denote claramente esta visión) como en verano, al igual que se intentará guardar en interior. Dependiendo del personaje y de su potencial reutilización podrían llegarse a guardar dos documentos en cada una de las estaciones. Esta decisión tiene que venir marcada por las necesidades de los usuarios y aquellos personajes que están en ese momento de "actualidad informativa". La televisión se mueve evidentemente por modas, de ahí que sea necesario identificar los personajes para realizar un mayor esfuerzo de selección sobre éstos.

\section{Las entidades como unidad de selección y con- servación}

Pueden igualmente ser visualizadas en un documento. Unos ejemplos ayudarán a entenderlo:

- Un conjunto de miembros de una entidad desarrollando una actividad que le es propia: asamblea de accionistas de una empresa, reunión de un grupo de gerencia, conjunto deportivo en una competición o un entrenamiento.

- Identificación de logotipos institucionales: salvo excepciones, la identificación de una entidad por medio de un logotipo no tendría por qué modificarse con el tiempo. La Cruz Roja para todos es un icono de ayuda sanitaria y humanitaria, pero realmente denota una entidad. Igualmente válido sería el escudo de un club, el anagrama de una empresa, etc. En este tipo de identificación, salvo que se modifique, no será necesario un control férreo con la ficha mostrada.

Sin embargo la visualización de un conjunto de miembros de una entidad sí que debe ser controlada, especialmente la de competiciones deportivas, donde es constante el visualizado de estas entidades y no siempre es necesaria su conservación. Existen televisiones que ofrecen información diaria de una serie de equipos deportivos. En estos casos se seleccionarían momentos 
Ficha de control de selección de personas

\begin{tabular}{|c|c|c|c|c|}
\hline Nombre & \multicolumn{4}{|c|}{ José Luís Rodríguez Zapatero } \\
\hline Entidad & \multicolumn{4}{|l|}{ PSOE } \\
\hline \multicolumn{5}{|c|}{ CONTROL TEMPORAL } \\
\hline Año & $\nabla 2007$ & Fecha & & $\nabla$ 03/abril \\
\hline Hiperenlace & \multicolumn{4}{|c|}{ url://1423.423.3532349 } \\
\hline \multicolumn{5}{|c|}{ DESCRIPCIÓN } \\
\hline Recurso & $\square$ & Total & & $\mathbf{\theta}$ \\
\hline Invierno & Verano & 田 & Interior & $\square$ \\
\hline
\end{tabular}

Figura 5. Ejemplo de utilización de la ficha propuesta

utilizar esta información para las solicitudes del presidente Rodríguez Zapatero con ropa y entorno atmosférico veraniegos, sin ser necesaria la conservación de nuevos recursos.

\section{Conclusiones}

No deseamos más que ahondar en la hipótesis inicial que hemos planteado como válida, demos-

determinados, como son al comienzo de la temporada, a mediados y al final, así como cuando existan recientes contrataciones y por lo tanto nuevos rostros inmersos en un conjunto. Y por supuesto, siempre serían en forma de recursos, ya que los totales son propios de personas físicas.

Esta observación lleva a otra más interesante y menos obvia: la indicación de una entidad que aglutine una serie de personas físicas no elimina la opción de indicar a cada uno de estos personajes por separado si son noticias por sí mismos, independientemente que tenga importancia o no su relación con la entidad matriz.

Sólo nos faltaría contestar a una cuestión: ¿cómo llevar a cabo esta labor? La ficha que se ha creado cuenta con la particularidad de que cada vez que un analista conserve una información onomástica deberá realizar el esfuerzo de anotar en ella los parámetros. No es una dedicación de tiempo excesiva, ya que se tarda más en analizar documentos audiovisuales. La consulta a la ficha ayudará a determinar si existen imágenes parecidas o muy similares del personaje, así como su actualidad. Esto provoca inicialmente una optimización del trabajo, y en cuanto a la recuperación documental se controla el ruido.

Existen otros elementos a tener en cuenta, como cuestiones legales (derecho a la intimidad, de la infancia), consideraciones técnicas (de calidad de reproducción) y evidentemente de validez potencial para las necesidades futuras del usuario.

Con el fin de facilitar la comprensión y entendimiento de la tabla ofrecemos un ejemplo y su explicación (ver figura 5).

Se indica el personaje y la entidad con la que está relacionado. A continuación se puede ver el año y la fecha en los que se ha conservado la última información sobre el mismo y los datos de descripción asociados. Si se accediera a otros años u otras fechas, la descripción cambiaría para identificar el otro registro. En este caso sabemos que tenemos una declaración, presumiblemente en plano medio, con ropa de verano, aunque abril no sea esta estación del año. Por lo tanto, se podrá trando por medio del análisis de teletipos y escaletas la existencia de saturación visual onomástica en televisión provocada por un evidente efecto Mateo peculiar.

A la vista de esta realidad y conociendo la frecuencia de aparición de los personajes, se propone controlar mediante la ficha presentada la información onomástica de los servicios de documentación en televisión.

La ficha optimiza medios humanos, espaciales y sustancialmente documentales, rebajando considerablemente el ruido en la recuperación. El tiempo destinado a su realización y mantenimiento no es comparable como prejuicio a las mejoras señaladas.

\section{Referencias}

Bonitz, Manfred. “Ten years Matthew effect for countries”. En: Scientometrics, v. 64, n. 39, pp. 375-379.

Caldera-Serrano, Jorge; Nuño-Moral, M. Victoria. Diseño de una base de datos de imágenes para televisión. Gijón: Trea. 2004. ISBN 84-9704100-3.

Hanford, Anne. "Normas recomendadas y procedimientos para seleccionar material de televisión". En: Panorama de los archivos audiovisuales: contribución a la puesta al día de las técnicas de archivo internacionales. Madrid: RTVE, 1986, pp. 125-130. ISBN 84-85259-19-X.

Havemann, Frank; Heinz, Michael; Wagner-Dobler, Roland. "Firm-like behaviour of journals? Scaling properties of their output and impact growth dynamics". En: Journal of the American Society for Information Science and Technology, 2005, v. 56, n. 1, pp. 3-12.

Hidalgo-Goyanes, Paloma. "Documentación audiovisual". En: GarcíaGutierrez, Antonio (ed.). Introducción a la documentación informativa y periodística. Sevilla: MAD, 1999, pp. 473-485. ISBN 84-8311-460-7.

Merton, Robert K. "The Matthew Effect in science: the reward and communication systems of science are considered". En: Science, 1968, v. 159, n. 3.810 , pp. $56-63$.

Price, Dereck J. de Solla. Little science, big science. New York: Columbia University Press, 1963.

Pritchard, Alan. "Statistical bibliography or bibliometrics". En: Journal of documentation, 1969 , v. 25, n. 4, pp. 348-369.

Strevens, Michael. "The role of the Matthew effect in science". En: Studies in history and philosophy of science, 2006, v. 37, n. 2, pp. 159-170.

Jorge Caldera-Serrano, Facultad de Biblioteconomía y Documentación, Universidad de Extremadura, Plazuela de Ibn Marwan, s/n, 06071 Badajoz.

jcalser@alcazaba.unex.es 


\title{
Applying Web 2.0: Innovation, Impact and Implementation
}

\author{
4-6 December \\ Olympia Grand Hall, London, UK
}

THE NO. 1 CONFERENCE FOR THE INFORMATION WORLD

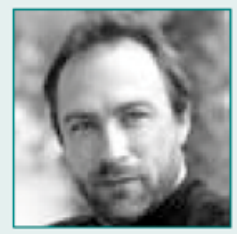

Opening keynote speaker

Jimmy Wales, Founder, Wikipedia \& Wikia

- Learn from over 100 international information leaders including: Euan Semple, Social Computing Expert: Greg Notess, Montana State University; Stephen Abram, SirsiDynix and Gunnar Sahlin, National Library of Sweden

- Discover what Web 2.0 means for you

- Experience Web 2.0 in practice with case studies from: Vodafone, BT, IBM, Drugscope, University of Sheffield, Mozilla Europe and more

- Gain new skills and competencies for information professional 2.0
- Hear from experts at more than 30 sessions covering all aspects of the information industry over 3 days

- Network with your peers from over 45 countries

- Develop your 'Web 2.0', 'Web Search', 'Research \& Competitive Intelligence' skills and knowledge in the workshops on Monday 3 December

- See the latest industry developments at the 2 co-located free exhibitions of over 250 online content and information management solutions providers

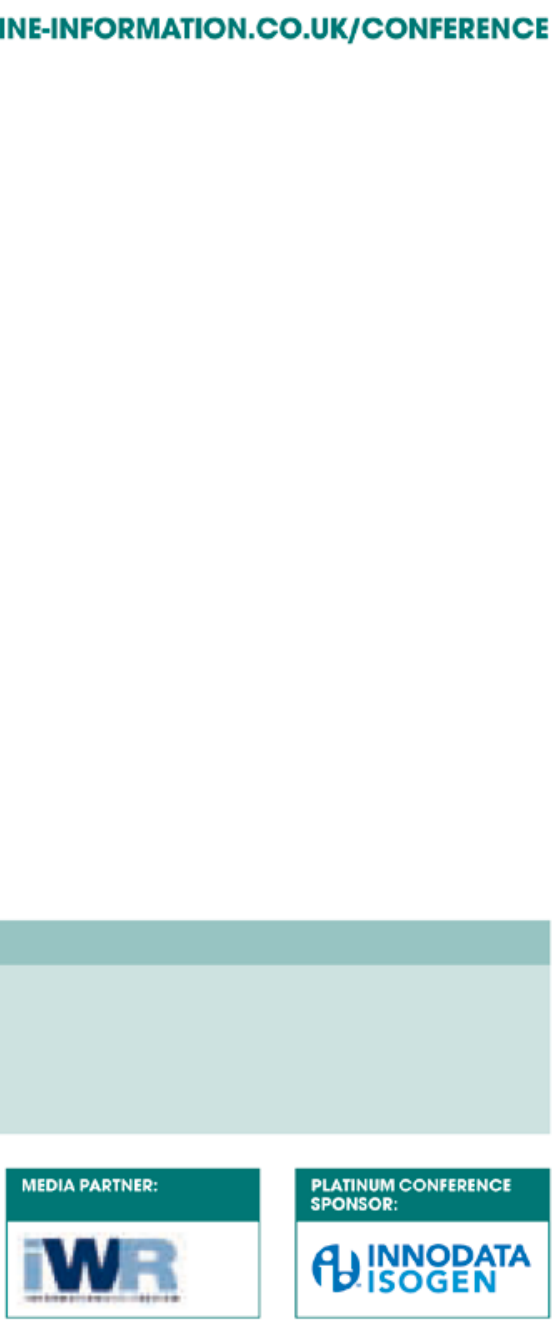

\begin{tabular}{|c|c|c|}
\hline \multicolumn{3}{|c|}{ SUPPORTED BY: } \\
\hline aiip & ALPSP & EST: \\
\hline & cilip & Cंsद \\
\hline dfid & EUSIDIC & Freepint \\
\hline \multicolumn{2}{|c|}{ A. The Intormation Architecture Irssititute } & $\begin{array}{l}\text { (9) } \\
\text { records } \\
\text { society }\end{array}$ \\
\hline QSLA & ESPIN & UKeiG \\
\hline
\end{tabular}
www.online-information.co.uk/conference 